\title{
Costunolide induces apoptosis and inhibits migration and invasion in H1299 lung cancer cells
}

\author{
MINYAN WEI $^{1 *}$, JIAJUN LI $^{1 *}$, JIANHUA QIU $^{1 *}$, YANYAN YAN $^{2}$, HUI WANG $^{3}$, ZENGBAO WU $^{4}$, YUN LIU $^{1}$, \\ XIAOYUN SHEN $^{1}$, CHAOYUE SU ${ }^{1}$, QIAORU GUO ${ }^{1}$, YANRUI PAN ${ }^{1}$, PEIQUAN ZHANG ${ }^{1}$ and JIANYE ZHANG ${ }^{1,5}$ \\ ${ }^{1}$ Guangdong Provincial Key Laboratory of Molecular Target and Clinical Pharmacology, \\ School of Pharmaceutical Sciences and the Fifth Affiliated Hospital, Guangzhou Medical University, \\ Guangzhou, Guangdong 511436; ${ }^{2}$ Department of Pharmacology, Institute of Respiratory and Occupational Diseases, \\ Collaborative Innovation Center for Cancer, Medical College, Shanxi Datong University, Datong, Shanxi 037009; \\ ${ }^{3}$ Department of Thoracic Surgery, Guangzhou Institute of Pediatrics/Guangzhou Women and Children's Medical Center, \\ Guangzhou Medical University, Guangzhou, Guangdong 510623; ${ }^{4}$ Key Laboratory of Xinjiang Phytomedicine Resources of \\ Ministry of Education, School of Pharmacy, Shihezi University, Shihezi, Xinjiang 832000; ${ }^{5}$ Key Laboratory of \\ Tropical Translational Medicine of Ministry of Education, Hainan Medical University, Haikou, Hainan 571199, P.R. China
}

Received September 13, 2019; Accepted February 26, 2020

DOI: $10.3892 / o r .2020 .7566$

\begin{abstract}
Costunolide being a sesquiterpene lactone, is known to have anticancer properties. The present study investigated the anticancer effects of costunolide against the H1299 human non-small-cell lung cancer (NSCLC) cell line. Inhibition of cell viability by costunolide was assessed via a MTT assay. Furthermore, the apoptotic rate was detected using Annexin $\mathrm{V} /$ propidium iodide labeling. A colony forming cell assay was performed to investigate the antiproliferative effects of costunolide. Wound healing and Transwell assays were performed to determine the inhibitory effects of costunolide on migration and invasion, respectively. Western blot analysis was undertaken to determine protein expression, and reverse transcription-quantitative PCR was performed to assess mRNA expression levels. The results demonstrated that costunolide inhibited the viability of H1299 cells, with a half maximal inhibitory concentration value of $23.93 \pm 1.67 \mu \mathrm{M}$ and induced cellular apoptosis in a dose-dependent manner. Furthermore, the colony formation, migrative and invasive abilities of the H1299 cells were inhibited in a dose- or time-dependent
\end{abstract}

Correspondence to: Professor Jianye Zhang or Dr Peiquan Zhang, Guangdong Provincial Key Laboratory of Molecular Target and Clinical Pharmacology, School of Pharmaceutical Sciences and the Fifth Affiliated Hospital, Guangzhou Medical University, Guangyi Avenue, Guangzhou, Guangdong 511436, P.R. China

E-mail: jianyez@163.com

E-mail: pqzhang@gzhmu.edu.cn

*Contributed equally

Key words: costunolide, anticancer, non-small-cell lung cancer, migration, invasion, epithelial-to-mesenchymal transition manner. The protein expression levels of E-cadherin increased and those of $\mathrm{N}$-cadherin decreased following treatment with costunolide, which suggested that costunolide inhibited epithelial-to-mesenchymal transition. The mRNA levels of B-Raf, E-cadherin, $\mathrm{N}$-cadherin, integrins $\alpha 2$ and $\beta 1$, as well as matrix metalloproteinases 2 were also found to be regulated costunolide. These findings indicate the potential of costunolide in the treatment of NSCLC.

\section{Introduction}

Lung cancer is one of the most common malignancies worldwide, of which $80-85 \%$ of all cases are non-small-cell lung cancer (NSCLC) (1). Clinically, very few patients with NSCLC are diagnosed at an early stage, when surgical resection is curative $(1,2)$. Thus, conventional chemotherapy and radiation therapy remain the mainstay of the treatment for lung cancer, and the development of novel anticancer drugs is critical.

Plants have long been considered a rich source of bioactive natural products, some of which exhibit potent activity as potential anticancer agents (3-7). Costunolide is a sesquiterpene lactone (Fig. 1A), which is extracted from various plant species, including genus Saussurea, Aucklandia and Inula (8-10). Costunolide exhibits a series of pharmacological activities, including anti-inflammatory (11), anti-allergic (12) and antimicrobial (13) effects. Notably, potent anticancer properties of costunolide have been identified in lung cancer and leukemia $(14,15)$.

Costunolide has been demonstrated to inhibit cell proliferation, induce apoptosis and inhibit angiogenesis in lung cancer cells and leukemia cells (16-18). However, the molecular mechanism by which costunolide inhibits tumor metastasis remains unclear. Thus, the present study aimed to investigate the in vitro antimetastatic effect of costunolide in the H1299 NSCLC cell line and assess the underlying molecular 
mechanisms. The results may be used as experimental evidence to support the role of costunolide against NSCLC.

\section{Materials and methods}

Cell culture and reagents. The H1299 human NSCLC cell line was purchased from iCell Bioscience Inc. and authenticated via short-tandem repeat profiling. Cells were cultured in RPMI-1640 medium (Zhejiang Senrui Biotechnology Co.,Ltd.) supplemented with $10 \%$ fetal bovine serum (FBS; Zhejiang Tianhang Biotechnology Co., Ltd.) and $1 \%$ penicillin-streptomycin liquid (Genom Biotech Pvt., Ltd.), and incubated in a $5 \% \mathrm{CO}_{2}$ humidified atmosphere at $37^{\circ} \mathrm{C}$. Costunolide, with a purity of $>98 \%$, was purchased from Nanjing Spring \& Autumn Biological Engineering Co., Ltd.

Cell viability assay. The MTT assay was performed to determine the effect of costunolide on cell viability. A total of $2 \times 10^{4} \mathrm{H} 1299$ cells were harvested and transferred into 96-well plates, at a final volume of $190 \mu \mathrm{l} /$ well. After $24 \mathrm{~h}$ incubation at $37^{\circ} \mathrm{C}, 10 \mu \mathrm{l}$ costunolide suspended in DMSO was added to the wells at final concentrations of 50, 25, 12.5, $6.25,3.13$ and $1.56 \mu \mathrm{g} / \mathrm{ml}$. After $68 \mathrm{~h}$ treatment, $20 \mu \mathrm{l}$ MTT $(5 \mathrm{mg} / \mathrm{ml})$ was added to each well and the plate was incubated for an additional $4 \mathrm{~h}$ at $37^{\circ} \mathrm{C}$. Following MTT incubation, the purple formazan crystals were dissolved using $100 \mu \mathrm{l}$ DMSO and viability was analyzed at a wavelength of $540 \mathrm{~nm}$, using a Model 550 Microplate reader (Bio-Rad Laboratories, Inc.) and $655 \mathrm{~nm}$ as the reference filter. The half maximal inhibitory concentration $\left(\mathrm{IC}_{50}\right)$ value was used to determine the growth-inhibitory effect of costunolide, which was calculated from the concentration-response curve using the Bliss method (SPSS version 16.0; SPSS, Inc.). Cell survival was calculated using a formula as previously described (3).

Annexin V/propidium iodide (PI) apoptosis assay. The Annexin V-FITC/PI Apoptosis Detection kit (Nanjing Keygen Biotech Co., Ltd.) was used to determine the apoptotic rate of H1299 cells, according to the manufacturer's protocol. A total of $5 \times 10^{5} \mathrm{H} 1299$ cells were cultured with $0,12.0,24.0$ and $48.0 \mu \mathrm{M}$ costunolide for $48 \mathrm{~h}$, harvested and resuspended in $0.5 \mathrm{ml}$ binding buffer (Nanjing Keygen Biotech Co., Ltd.) containing Annexin V (1:50) and $40 \mathrm{ng} / \mathrm{sample}$ PI for $30 \mathrm{~min}$ at $37^{\circ} \mathrm{C}$ in the dark. The stained samples were analyzed using a flow cytometer (Beckman Coulter, Inc.) and CytExpert software version 2.2 (Beckman Coulter, Inc.). The apoptotic rate was determined by dividing the number of apoptotic cells by the number of total observed cells and multiplying by 100 .

Colony forming cell (CFC) assay. H1299 cells were split and seeded into 12 -well plates at a density of 400 cells/plate. Once clones of $\sim 30$ cells were formed, they were treated with $24.0 \mu \mathrm{M}$ costunolide for $0,24,48,72$ and $96 \mathrm{~h}$. In another experiment, cells were treated with varying concentrations of costunolide $(0,6.0,12.0,24.0$ and $48.0 \mu \mathrm{M})$ for $48 \mathrm{~h}$. The wells were washed with PBS three times, fixed with analytically pure methanol (Shanghai Titan Scientific Co., Ltd.) for $30 \mathrm{~min}$ and then stained with $0.05 \%$ crystal violet. After staining for $15 \mathrm{~min}$ at room temperature, crystal violet was removed and the wells were cleaned using running water. Plates were photographed after drying. All experiments were performed in triplicate.

Wound healing assay. H1299 cells were digested using trypsin and resuspended in serum-free medium. Cells were seeded into 6-well plates and allowed to reach $100 \%$ confluence overnight. Subsequently, linear wounds were scratched in the cell monolayer using a pipette tip and the wounded cell layer was washed three times with PBS to remove detached cells. Cells were incubated with $0,12.0,24.0$ and $48.0 \mu \mathrm{M}$ concentrations of costunolide, and wounds were observed and captured using a light microscope (x40) after 0,24 and $48 \mathrm{~h}$ of incubation, respectively. Cell motility was determined according to the percentage of the repaired wound area. The percentage wound closure was calculated as follows: Migrated cell surface area/total surface area x100 (19).

Invasion assay. The insert of a Transwell apparatus (Corning Inc.) was pre-coated with 25\% Matrigel (Corning Inc.), which was diluted with serum-free RPMI-1640. H1299 cells were seeded in the upper chamber of the Transwell apparatus at a density of $8 \times 10^{3}$ cells/chamber, in $200 \mu 1$ serum-free RPMI-1640 medium containing 0, 12.0, 24.0 and $48.0 \mu \mathrm{M}$ concentrations of costunolide. A total of $600 \mu 1$ RPMI-1640 medium, containing 10\% FBS was added to the lower chamber, which acted as a chemoattractant. After 24 and $48 \mathrm{~h}$, cells that migrated into the lower chamber were fixed with analytically pure methanol and stained with $0.05 \%$ crystal violet at room temperature for $30 \mathrm{~min}$. Cells on the top layer were removed using a cotton swab, and images of the migrated cells were captured using a light microscope (x200). A total of nine random fields were acquired to quantify attached and migrated cells. ImageJ software version 1.51j8 (http://imagej. nih.gov/ij) was used to quantify the cell number. Cell counts were expressed as the mean number of cells/field of view (20).

Reverse transcription-quantitative (RT- $q$ )PCR. Total RNA was extracted from H1299 cells following treatment with 0 , 12.0, 24.0 and $48.0 \mu \mathrm{M}$ concentrations of costunolide for 6 and $12 \mathrm{~h}$ at room temperature, using TRIzol ${ }^{\circledR}$ reagent (Thermo Fisher Scientific, Inc.), according to the manufacturer's instructions. Total RNA was reverse transcribed into cDNA using the PrimeScript $^{\mathrm{TM}}$ RT Master mix (Takara Bio, Inc.), according to the manufacturer's instructions. The forward and reverse primer sequences were designed by Takara Bio, Inc. (Table SI), in order to detect the expression levels of B-Raf, integrin $\alpha 2$, integrin $\beta 1$, matrix metalloproteinase 2 (MMP2), N-cadherin and E-cadherin. qPCR was subsequently performed using SYBR $^{\circledast}$ Premix Ex Taq ${ }^{\mathrm{TM}}$ (Tli RNase H Plus; Takara Bio, Inc.) and QuantStudio 5 (Thermo Fisher Scientific, Inc.), according to the manufacturer's instructions. The RT-qPCR program was set as initial denaturation at $95^{\circ} \mathrm{C}$ for $30 \mathrm{sec}$; then 40 reaction cycles were followed by denaturation at $95^{\circ} \mathrm{C}$ for $5 \mathrm{sec}$, annealing at $60^{\circ} \mathrm{C}$ for $34 \mathrm{sec}$, and then elongation at $72^{\circ} \mathrm{C}$ for $30 \mathrm{sec}$. mRNA expression levels were quantified using the $2^{-\triangle \Delta C q}$ method and normalized to the internal reference gene GAPDH (21).

Western blotting. After culturing with $0,12.0,24.0$ and $48.0 \mu \mathrm{M}$ concentrations of costunolide for $48 \mathrm{~h}$ at $37^{\circ} \mathrm{C}, \mathrm{H} 1299$ 
cells from different samples were collected and washed twice with ice-cold PBS. Total protein was extracted from H1299 cells using lysis buffer, which was composed of 1X RIPA Lysis Buffer (Beyotime Institute of Biotechnology) and 100X PMSF (Cell Signaling Technology, Inc.), supplemented with 1X Proteinase Inhibitor Cocktail and phenylmethylsulfonyl fluoride (Cell Signaling Technology, Inc.). Equal amounts of protein $(25 \mu \mathrm{g} / \mathrm{lane})$ were separated via SDS-PAGE on an 8-12\% gel, and the separated proteins were subsequently transferred onto a polyvinylidene membrane (EMD Millipore). The membranes were blocked with Tris-buffered saline and $0.05 \%$ Tween-20 (TBST) supplemented with 5\% dried non-fat milk at room temperature for $1 \mathrm{~h}$. Subsequently, the membranes were incubated with primary antibodies against $\mathrm{N}$-Cadherin (cat. no. 13116; Cell Signaling Technology, Inc.) with dilution ratio of 1:1,000, E-Cadherin (cat. no. 3195; Cell Signaling Technology, Inc.) with dilution ratio of 1:1,000 and GAPDH (cat. no. MB001; Bioworld Technology, Inc.) with dilution ratio of $1: 10,000$ overnight at $4^{\circ} \mathrm{C}$. Membranes were washed three times with TBST buffer. Following the primary incubation, membranes were incubated with horseradish peroxidase (HRP)-conjugated secondary antibodies (cat. no. 7074; Cell Signaling Technology, Inc.) with dilution ratio of 1:2,000 for $2 \mathrm{~h}$ at room temperature. Protein bands were visualized using the Western Lightning ${ }^{\circledR}$ Plus-ELC kit (PerkinElmer, Inc.) and exposed using ChemiDoc ${ }^{\mathrm{TM}}$ XRS+ (Bio-Rad Laboratories, Inc.). The blots were quantified using ImageJ software version $1.51 \mathrm{j} 8$.

Statistical analysis. Statistical analysis was performed using SPSS software ver. 16.0 (SPSS, Inc.). Significance was tested using one-way ANOVA and Tukey's post hoc test for multiple comparisons. All data are presented as the mean \pm standard deviation. $\mathrm{P}<0.05$ was considered to indicate a statistically significant difference. All experiments were performed in triplicate unless otherwise stated.

\section{Results}

Costunolide exerts a notable inhibitory effect against $\mathrm{H} 1299$ cells. The inhibition of cell viability by costunolide was assessed via MTT assay. Costunolide was demonstrated to inhibit the viability of $\mathrm{H} 1299$ cells, with an $\mathrm{IC}_{50}$ value of $23.93 \pm 1.67 \mu \mathrm{M}$. The inhibition occurred in a dose-dependent manner (Fig. 1B).

Costunolide induces apoptosis in H1299 cells. H1299 cells were treated with $0,12.0,24.0$ and $48.0 \mu \mathrm{M}$ of costunolide for $48 \mathrm{~h}$, in order to investigate whether the antitumor effect of costunolide against H1299 cells was mediated via apoptosis. The apoptotic rate was assessed via flow cytometry, based on Annexin V and PI staining. The apoptotic rates were as follows: $6.26 \pm 1.08,7.94 \pm 1.49,10.01 \pm 1.29$ and $22.68 \pm 3.56 \%$ for $0,12.0,24.0$ and $48.0 \mu \mathrm{M}$ costunolide, respectively. The results showed that the apoptotic rate between the control and $24.0 \mu \mathrm{M}$ group was significantly different, as was that between the 24.0 and $48.0 \mu \mathrm{M}$ groups (Fig. 2).

Costunolide decreases colony formation of H1299 cells. The CFC assay was performed to further investigate the

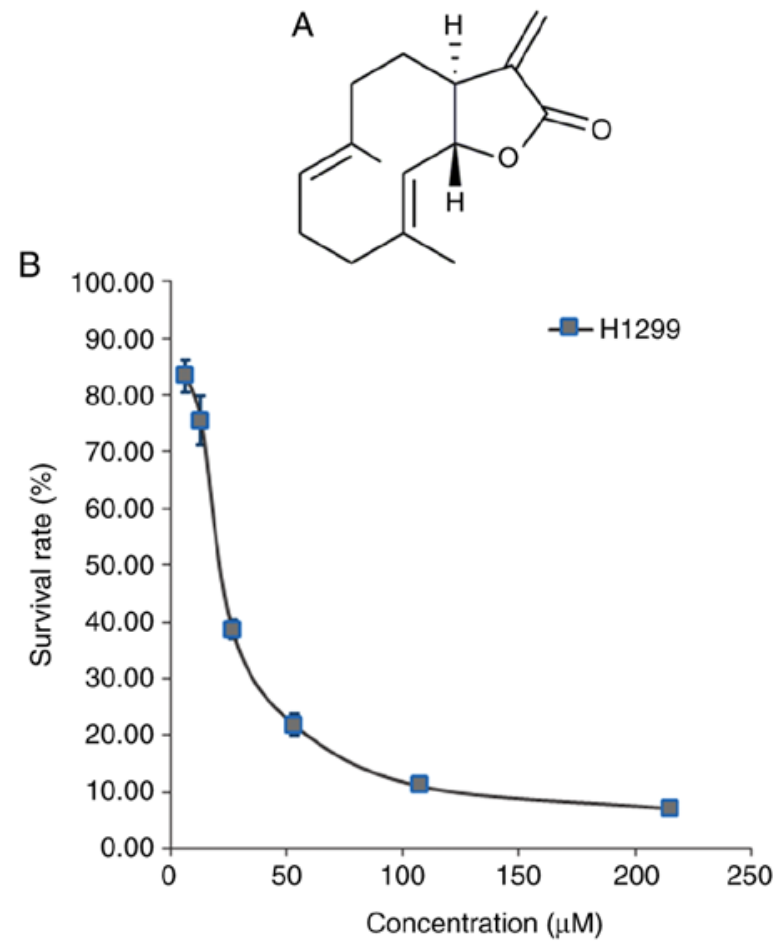

Figure 1. Chemical structure of costunolide and its ability to inhibit H1299 cell viability. (A) Chemical structure of costunolide. (B) H1299 lung cancer cells were cultured with costunolide at different concentrations for $24 \mathrm{~h}$ and cell viability was assessed via MTT assay.

antiproliferative effects of costunolide. The results demonstrated that incubation of H1299 cells with 6.0, 12.0, 24.0 and $48.0 \mu \mathrm{M}$ costunolide for $48 \mathrm{~h}$, and with $24.0 \mu \mathrm{M}$ costunolide for $0,24,48,72$ and $96 \mathrm{~h}$ decreased the colony formation of H1299 cells in a dose- and time-dependent manner, as revealed by reductions in the colony numbers and sizes (Fig. 3).

Costunolide decreases the migrative ability of $\mathrm{H1} 299$ cells. Wound healing assays were performed to assess the effect of costunolide on the migrative ability of $\mathrm{H} 1299$ cells. H1299 cells were treated with 12.0, 24.0 and $48.0 \mu \mathrm{M}$ costunolide for $24 \mathrm{~h}$, and the mobility ratios with respect to the untreated control were as follows: $16.16 \pm 1.39,12.35 \pm 2.32$ and $5.34 \pm 0.88 \%$, respectively. Following treatment of $\mathrm{H} 1299$ cells with 12.0, 24.0 and $48.0 \mu \mathrm{M}$ of costunolide for $48 \mathrm{~h}$, the mobility ratios were as follows: $39.89 \pm 3.85,32.90 \pm 3.04$ and $18.49 \pm 1.62 \%$, respectively (Fig. 4). These results suggest that costunolide markedly inhibits H1299 cell migration in a dose-dependent manner.

Costunolide decreases the invasive ability of H1299 cells. Invasion is another process associated with cancer proliferation and metastasis (22). Transwell assays were performed to assess the effect of costunolide on the invasive ability of H1299 cells. Consistent with the results of the migration assay, costunolide significantly inhibited the invasive ability of H1299 cells. Following the treatment of H1299 cells with 12.0, 24.0 and $48.0 \mu \mathrm{M}$ costunolide for $48 \mathrm{~h}$, and with $24.0 \mu \mathrm{M}$ costunolide for 24 and $48 \mathrm{~h}$, the number of invaded cells significantly decreased compared with the untreated control (Fig. 5). These results indicate that costunolide decreases H1299 cell invasion in a dose- and time-dependent manner. 

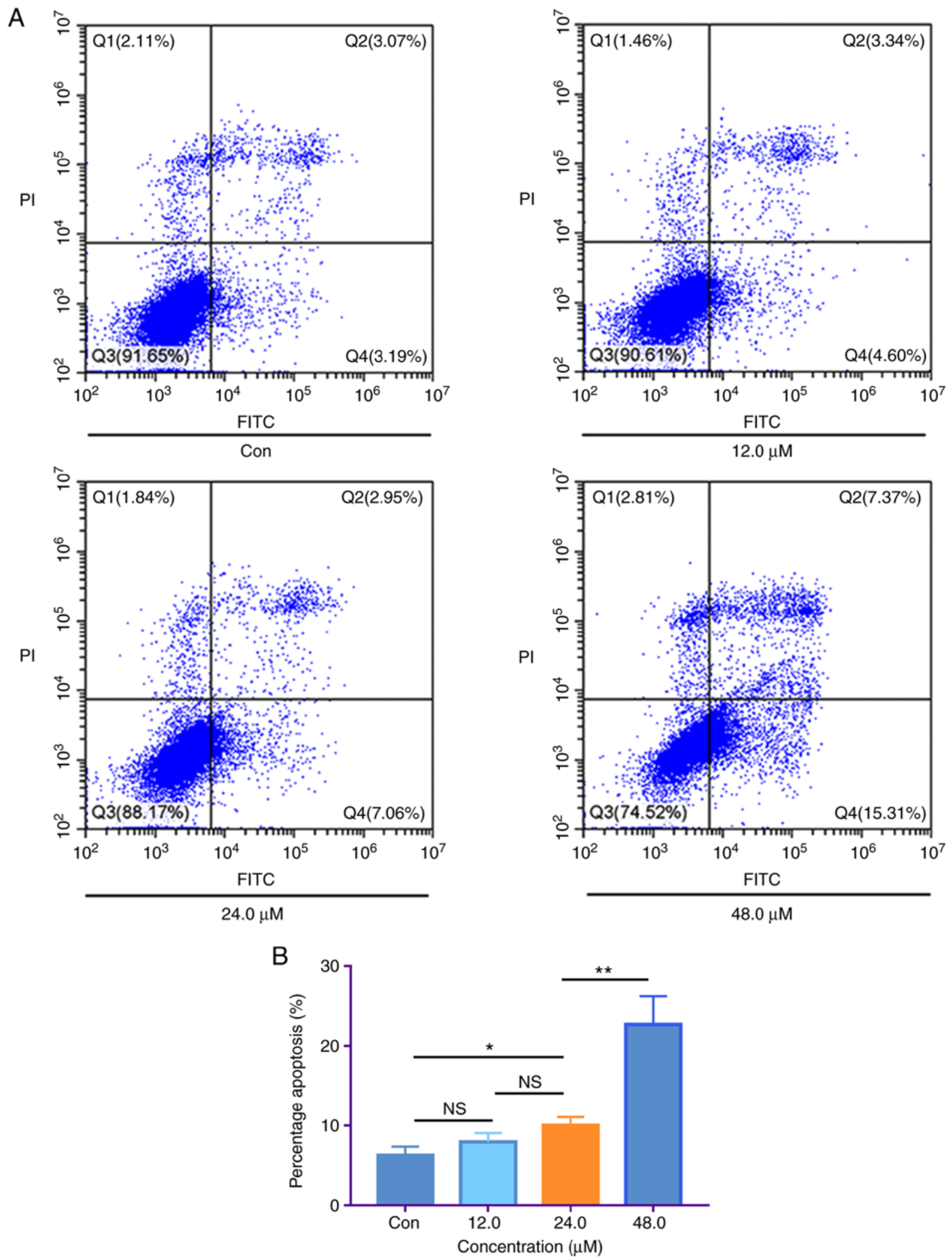

Figure 2. Costunolide induces apoptosis of H1299 lung cancer cells in vitro. (A) H1299 cells were treated with costunolide for 48 h and apoptosis was detected via fluorescence-activated cell sorting. Representative images are displayed. (B) Data are presented as the mean \pm standard deviation ( $\mathrm{n}=3$ ). Differences between concentrations were tested using one-way ANOVA and Tukey's post hoc tests. ${ }^{*} \mathrm{P}<0.05,{ }^{* *} \mathrm{P}<0.01$; NS, not significant. Con, control.

Costunolide regulates metastasis- and proliferationassociated mRNA expression. RT-qPCR analysis was performed to determine whether the antiproliferative, antimigration and anti-invasive properties of costunolide were associated with changes in specific mRNA levels. Following the treatment of H1299 cells with 12.0, 24.0 and $48.0 \mu \mathrm{M}$ costunolide for $6 \mathrm{~h}$, the mRNA expression levels of E-cadherin were demonstrated to be upregulated (Fig. 6A), 
A

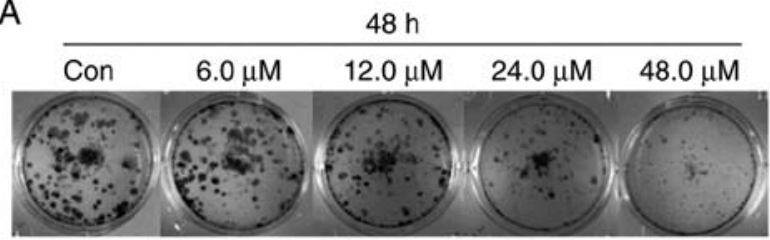

B

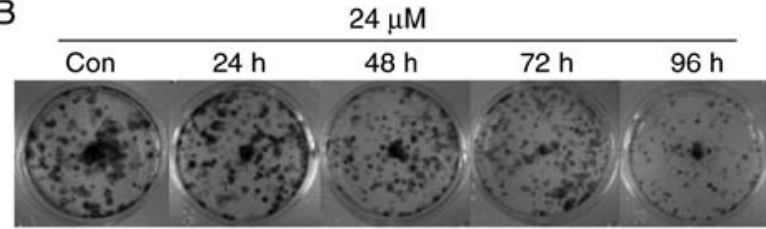

Figure 3. Costunolide inhibits colony formation of H1299 lung cancer cells in vitro. (A) H1299 cells were treated with different concentrations of costunolide for $48 \mathrm{~h}$ and colony efficiency was observed via a colony forming cell assay. (B) H1299 cells were treated with $24.0 \mu \mathrm{M}$ costunolide for different time periods. Con, control.

A

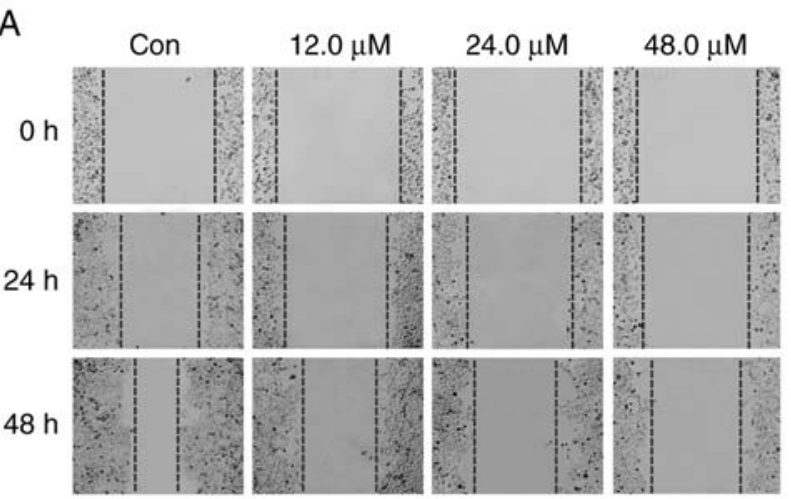

B

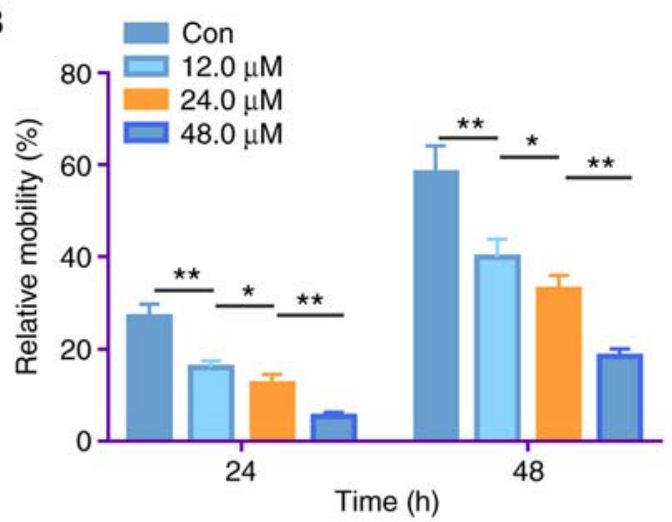

Figure 4. Costunolide treatment decreases the migrative ability of H1299 lung cancer cells in vitro. (A) H1299 cells were treated with different concentrations of costunolide for $24 \mathrm{~h}$ and the mobility rates were observed via wound healing assays. (B) Data are presented as the mean \pm standard deviation $(n=3)$. Differences between concentrations were tested using one-way ANOVA and Tukey's post hoc tests. ${ }^{*} \mathrm{P}<0.05,{ }^{* *} \mathrm{P}<0.01$. Con, control.

and the mRNA expression levels of $\mathrm{N}$-cadherin, integrin $\alpha 2$, integrin $\beta 1$, MMP2 and B-Raf were downregulated compared with the untreated control in a dose-dependent manner (Fig. 6B-F). Consistent with these results, treatment of H1299 cells with the same concentration gradient of costunolide for $12 \mathrm{~h}$ regulated the same mRNA levels in a dose-dependent manner (Fig. 6).
Costunolide regulates epithelial-to-mesenchymal transition (EMT)-associated protein expression. EMT is considered to be a key process in cancer metastasis, in which E-cadherin and $\mathrm{N}$-cadherin are markers (23). In order to investigate whether costunolide is able to inhibit the EMT of H1299 cells, western blotting was performed to detect the protein expression levels of E-cadherin and N-cadherin. Following treatment of H1299 cells with $12.0,24.0$ and $48.0 \mu \mathrm{M}$ costunolide for $48 \mathrm{~h}$, the protein expression levels of E-cadherin increased, while those of $\mathrm{N}$-cadherin decreased compared with those in the untreated control (Fig. 7). These results suggest that costunolide has the ability to significantly inhibit the EMT of H1299 cells.

\section{Discussion}

Costunolide is a sesquiterpene lactone (24), which has been reported to exert antiproliferative effects against a wide range of cancer cells, including gastric cancer (25), leukemia (26), colorectal cancer (27) and lung cancer (16). The results of the present study demonstrated that costunolide inhibited the proliferation of H1299 NSCLC cells, with an $\mathrm{IC}_{50}$ value of $23.93 \pm 1.67 \mu \mathrm{M}$. These results are consistent with the findings of a previous study on MDA-MB-231 cells (28). Apoptosis is a type of programmed cell death designed to eliminate redundant, damaged or even infected cells in order to maintain homeostasis (29). The apoptotic effect of costunolide against cancer cells has previously been reported $(9,16)$. The results of the present study demonstrated that costunolide induced a dose-dependent increase in the apoptotic ratio of H1299 cells, indicating the key role of apoptosis in the antiproliferative effects of costunolide.

The CFC assay indicated that costunolide decreased colony formation by $\mathrm{H} 1299$ cells, in an apparently dose- and time-dependent manner. B-Raf is one of the most commonly mutated proto-oncogenes, which plays a key role in the development of several types of cancer of high clinical impact (30). The results of the present study demonstrated that B-Raf mRNA expression levels were dose-dependently downregulated by costunolide in H1299 lung cancer cells.

Metastasis involves a series of consecutive events, in which cancer cells migrate, invade and eventually colonize distant regions (31). The results of the present study demonstrated that costunolide inhibited cancer migration in a dose-dependent manner, and invasion in a dose- and time-dependent manner.

EMT, a biological process in which epithelial features are lost while mesenchymal features are acquired (22), is closely associated with the migration and invasion of cancer cells. E-cadherin is considered to be an epithelial marker and N-cadherin is a key mesenchymal marker of EMT (23). In the present study, the RT-qPCR results demonstrated that the underlying molecular mechanism of action of costunolide may involve regulation of the mRNA expression of cadherin. Increased E-cadherin protein expression levels and decreased $\mathrm{N}$-cadherin protein expression levels in the H1299 lung cancer cells confirmed that costunolide has the potential to inhibit EMT in vitro. In the present study, the mRNA expression levels of integrins $\alpha 2$ and $\beta 1$ were detected. Integrins are adhesive receptors located on the cell surface, which mediate cell adhesion (32). Furthermore, MMPs induce cancer cell migration via degradation of the extracellular matrix (33). In 
A

$48 \mathrm{~h}$

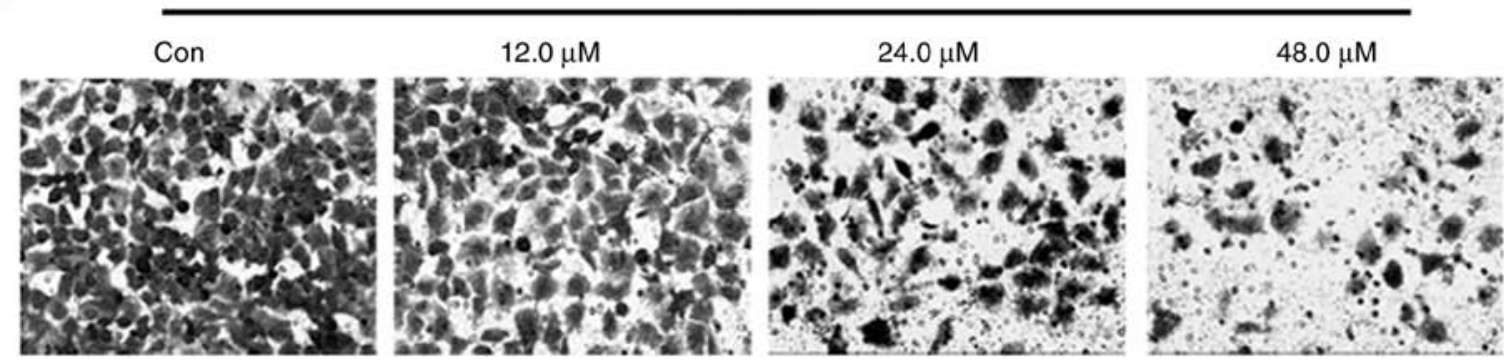

B

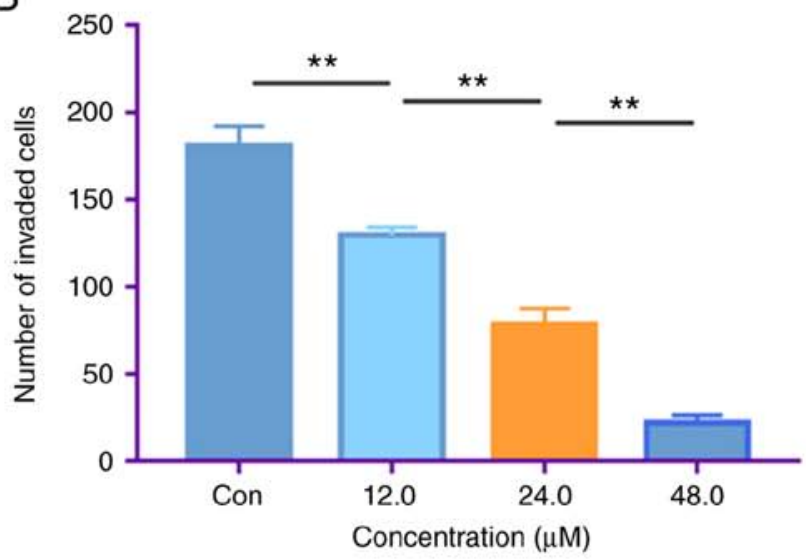

C
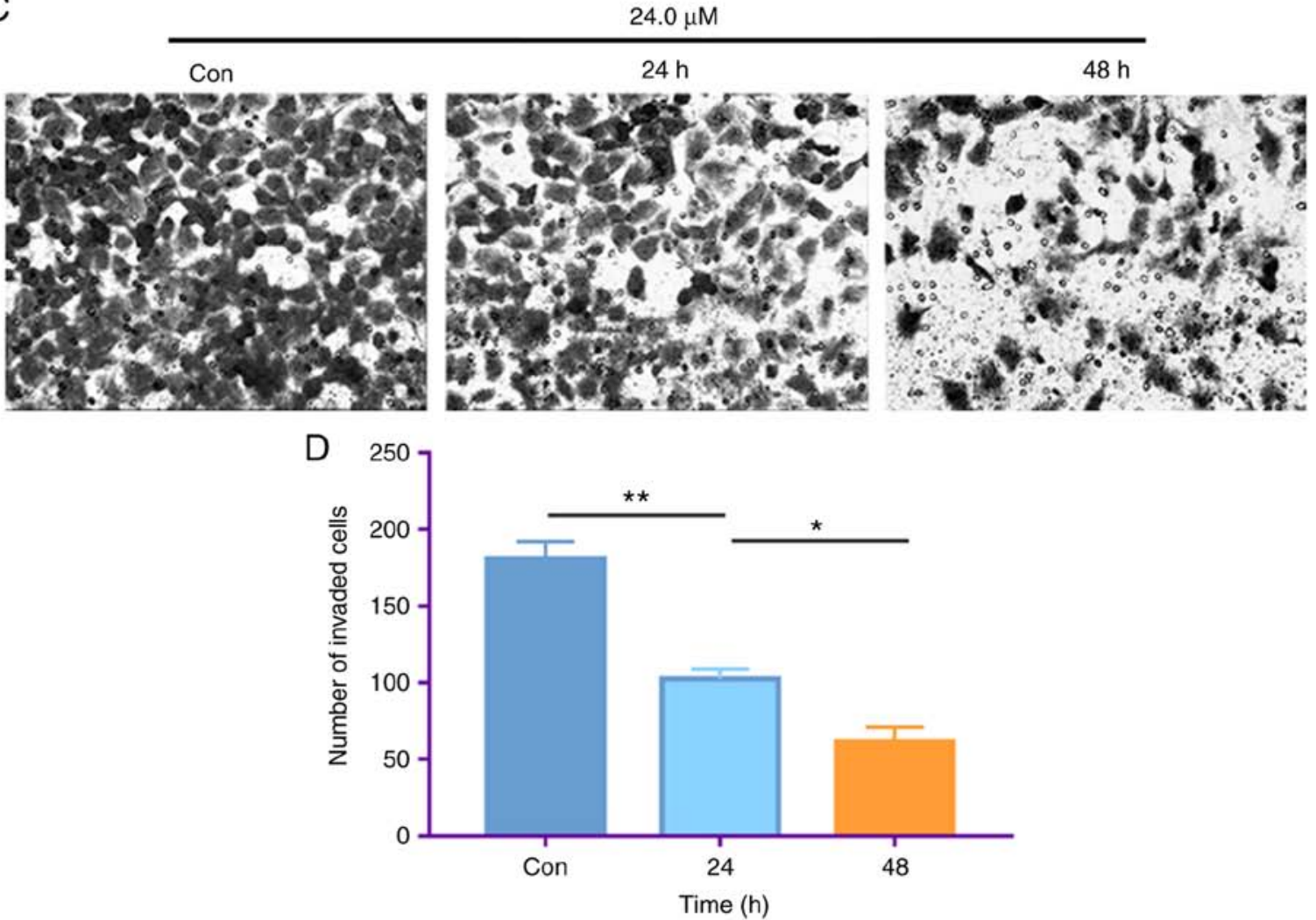

Figure 5. Costunolide decreases the invasive ability of H1299 lung cancer cells in vitro. (A) The invasive ability of H1299 cells was detected via Transwell assay. Following treatment of H1299 cells with different concentrations of costunolide for $48 \mathrm{~h}$, the number of invaded cells decreased in a dose-dependent manner. (B) Quantitative results presented as the mean \pm standard deviation $(\mathrm{n}=3)$. (C) Following treatment of H1299 cells with $24.0 \mu \mathrm{M}$ costunolide for 24 and $48 \mathrm{~h}$, the number of invaded cells decreased in a time-dependent manner. (D) Quantitative results presented as the mean \pm standard deviation ( $\mathrm{n}=3$ ). Differences between (B) concentrations and (D) times were tested using one-way ANOVA and Tukey's post hoc tests. ${ }^{*} \mathrm{P}<0.05,{ }^{* *} \mathrm{P}<0.01$. Con, control.

the present study, costunolide dose-dependently downregulated the mRNA expression levels of integrins $\alpha 2$ and $\beta 1$, as well as MMP2 in H1299 cells, which indicated the inhibitory potential of costunolide against NSCLC metastasis. It remains unclear how costunolide influences other genes associated with EMT. In future studies, the present research team will 

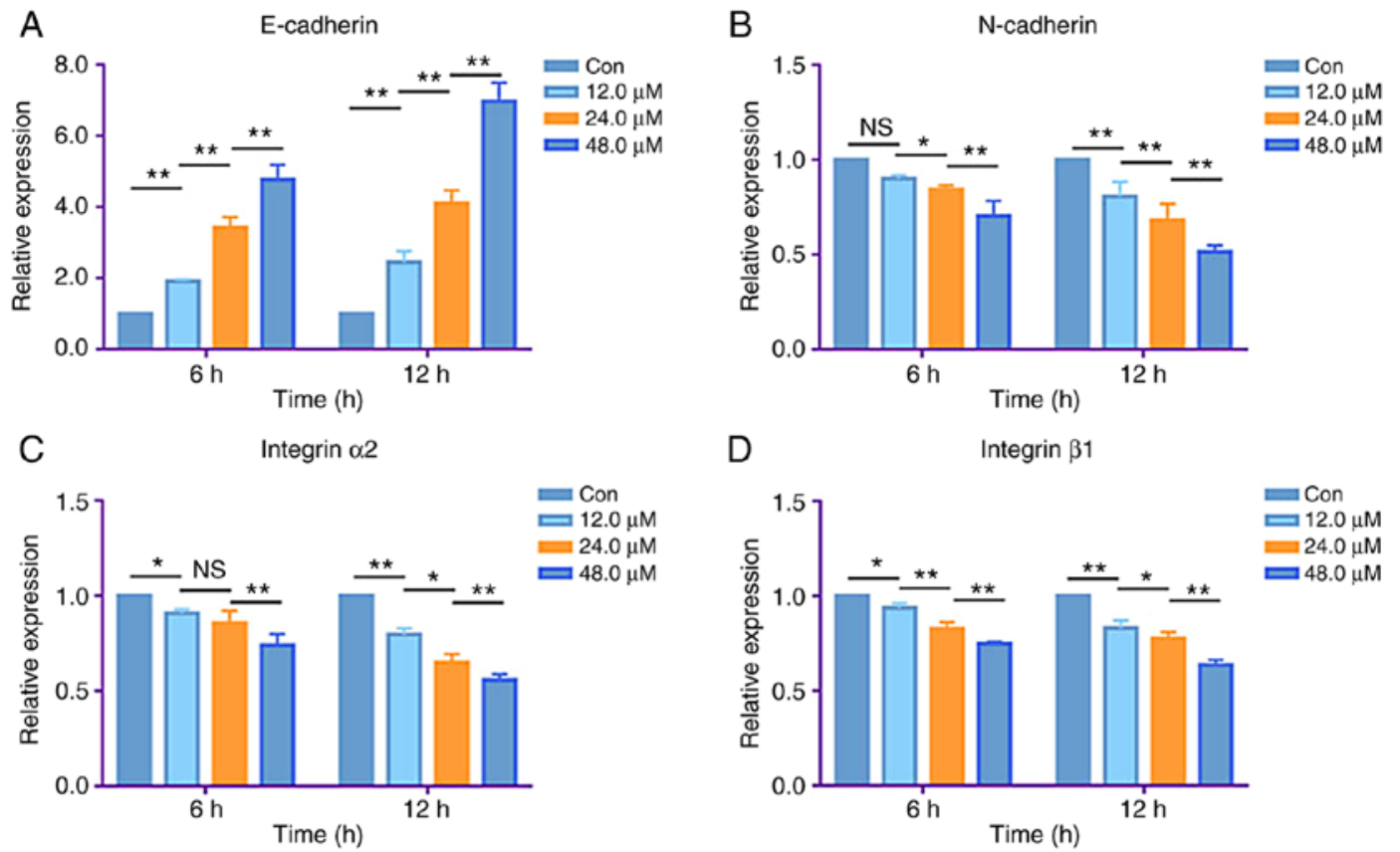

D
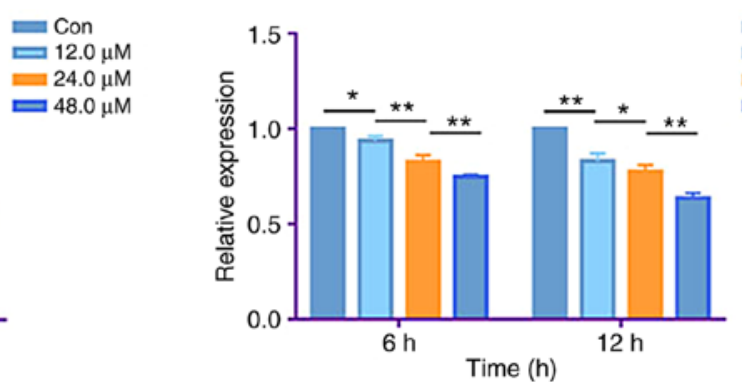

Con

$=12.0 \mu \mathrm{M}$

$24.0 \mu \mathrm{M}$

已 $48.0 \mu \mathrm{M}$

E

MMP2

F

B-Raf
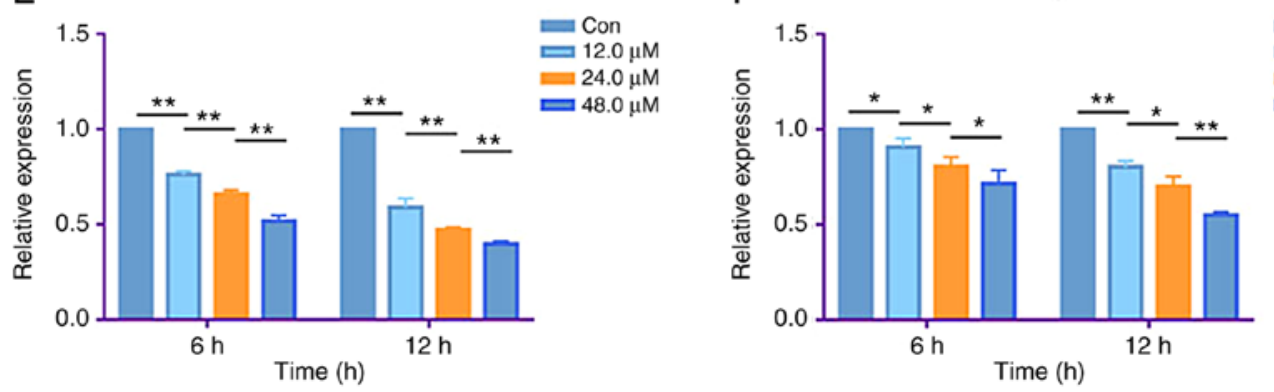

Figure 6. Costunolide regulates metastasis- and proliferation-associated mRNA expression levels of H1299 lung cancer cells in vitro. H1299 cells were treated with different concentrations of costunolide for 6 and $12 \mathrm{~h}$. (A) The mRNA expression levels of E-cadherin were upregulated in a dose-dependent manner. The mRNA expression levels of (B) N-cadherin, (C) integrin $\alpha 2$, (D) integrin $\beta 1$, (E) MMP2 and (F) B-Raf were downregulated in a dose-dependent manner. Data are presented as the mean \pm standard deviation $(n=3)$. Differences between concentrations were tested using one-way ANOVA and Tukey's post hoc tests. ${ }^{*} \mathrm{P}<0.05,{ }^{* *} \mathrm{P}<0.01 ; \mathrm{NS}$, not significant. MMP2, matrix metalloproteinase-2; con, control.

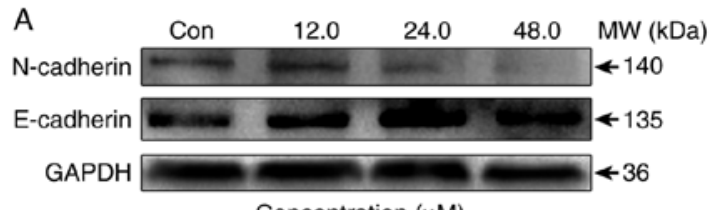

Concentration $(\mu \mathrm{M})$

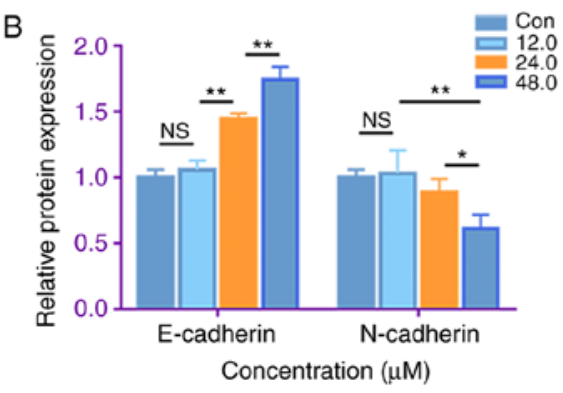

Figure 7. Costunolide regulates epithelial-to-mesenchymal transitionassociated protein expression of H1299 lung cancer cells in vitro. (A) Following the treatment of H1299 cells with different concentrations of costunolide for $48 \mathrm{~h}$, E-cadherin protein expression was increased, while $\mathrm{N}$-cadherin was decreased. Representative blots are shown. (B) Data are presented as the mean \pm standard deviation $(n=3)$. Differences between concentrations were tested using one-way ANOVA and Tukey's post hoc tests. ${ }^{*} \mathrm{P}<0.05,{ }^{* *} \mathrm{P}<0.01$; NS, not significant. Con, control.

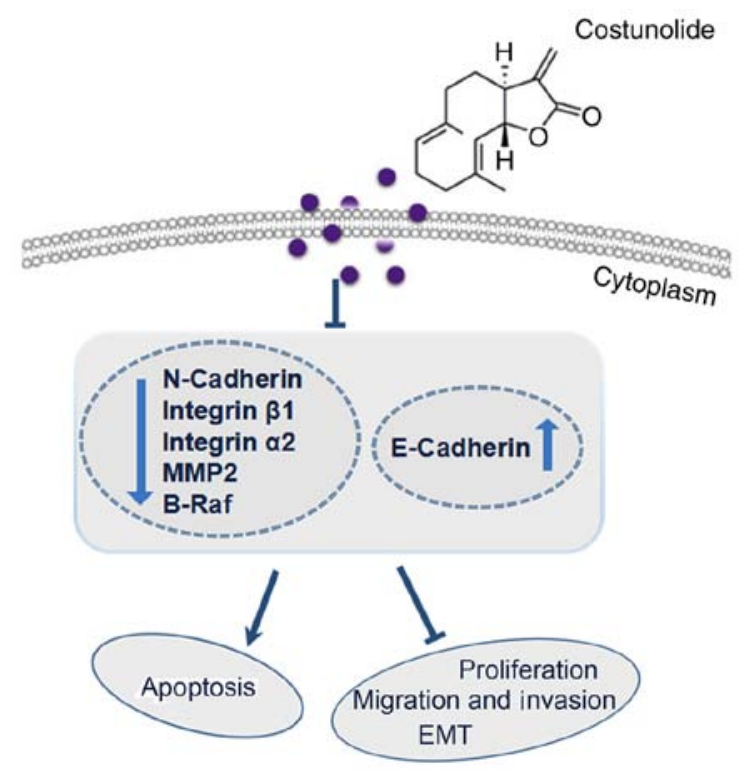

Figure 8. Brief summary of molecular mechanisms involved in costunolide-induced antiproliferative, antimigration and anti-invasive effects against the H1299 human non-small-cell lung cancer cell line. MMP2, matrix metalloproteinase-2; EMT, epithelial-to-mesenchymal transition. 
use RNA sequencing or microarrays to observe the landscape gene expression changes caused by costunolide and confirm the efficacy of costunolide in the treatment of NSCLC. Also, determining the efficacy of costunolide in vivo will help to elucidate the anticancer activity of costunolide. The potential antiproliferative, antimigration and anti-invasive molecular mechanisms of costunolide revealed in the present study are summarized in Fig. 8.

In conclusion, the present study revealed the antiproliferation, apoptosis-inducing, antimigration and anti-invasion effects of costunolide against H1299 human NSCLC cells. The results suggest that costunolide may have the potential to inhibit the EMT of H1299 cells in vitro.

\section{Acknowledgements}

Not applicable.

\section{Funding}

This work was supported by National Natural Science Foundation of China (grant nos. 81773888, U1903126 and 81902152), Fund of Guangzhou Science and Technology Program (grant no. 201707010048) and Fund from Guangzhou Institute of Pediatrics/Guangzhou Women and Children's Medical Center (grant no: IP-2018-012).

\section{Availability of data and materials}

Samples of costunolide are available from the authors. The datasets used and analyzed during the current study are available from the corresponding author on reasonable request.

\section{Authors' contributions}

MW, JZ and PZ conceived and designed the experiments; JL, JQ, YY, YL, XS and CS performed the experiments; MW, HW, ZW, YP and PZ analyzed the data; QG, WZ and JL contributed analysis tools and planned the experiments; JL, JQ and JZ wrote the paper. All authors read and approved the final manuscript.

\section{Ethics approval and consent to participate}

Not applicable.

\section{Patient consent for publication}

Not applicable.

\section{Competing interests}

The authors declare that they have no competing interests.

\section{References}

1. Osmani L, Askin F, Gabrielson E and Li QK: Current WHO guidelines and the critical role of immunohistochemical markers in the subclassification of non-small cell lung carcinoma (NSCLC): Moving from targeted therapy to immunotherapy. Semin Cancer Biol 52: 103-109, 2018.
2. Siegel RL, Miller KD and Jemal A: Cancer statistics, 2018. CA Cancer J Clin 68: 7-30, 2018.

3. Lin M, Tang S, Zhang C, Chen H, Huang W, Liu Y and Zhang J: Euphorbia factor L2 induces apoptosis in A549 cells through the mitochondrial pathway. Acta Pharm Sin B 7: 59-64, 2017.

4. Zhang JY, Lin MT, Tung HY, Tang SL, Yi T, Zhang YZ, Tang YN Zhao ZZ and Chen HB: Bruceine D induces apoptosis in human chronic myeloid leukemia K562 cells via mitochondrial pathway. Am J Cancer Res 6: 819-826, 2016.

5. Yan YY, Bai JP, Xie Y, Yu JZ and Ma CG: The triterpenoid pristimerin induces U87 glioma cell apoptosis through reactive oxygen species-mediated mitochondrial dysfunction. Oncol Lett 5: 242-248, 2013.

6. Li JJ, Yan YY, Sun HM, Liu Y, Su CY, Chen HB and Zhang JY: Anti-cancer effects of pristimerin and the mechanisms: A critical review. Front Pharmacol 10: 746, 2019.

7. Liu Y, Sun H, Makabel B, Cui Q, Li J, Su C, Ashby CR Jr, Chen Z and Zhang J: The targeting of noncoding RNAs by curcumin: Facts and hopes for cancer therapy (Review). Oncol Rep 42: 20-34, 2019.

8. Cao K, Qian W, Xu Y, Zhou Z, Zhang Q and Zhang X: A new sesquiterpenoid from Saussurea lappa roots. Nat Prod Res 30: 2160-2163, 2016.

9. Rasul A, Yu B, Yang LF, Arshad M, Khan DM, Ma T and Yang H: Costunolide, a sesquiterpene lactone induces $\mathrm{G} 2 / \mathrm{M}$ phase arrest and mitochondria-mediated apoptosis in human gastric adenocarcinoma SGC-7901 cells. J Med Plants Res 6: 1191-1200, 2011.

10. Garayev E, Herbette G, Di Giorgio C, Chiffolleau P, Roux D, Sallanon H, Ollivier E, Elias R and Baghdikian B: New sesquiterpene acid and inositol derivatives from Inula montana L. Fitoterapia 120: 79-84, 2017.

11. Park E, Song JH, Kim MS, Park SH and Kim TS: Costunolide, a sesquiterpene lactone, inhibits the differentiation of pro-inflammatory CD4(+) T cells through the modulation of mitogen-activated protein kinases. Int Immunopharmacol 40: 508-516, 2016.

12. Lee BK, Park SJ, Nam SY, Kang S, Hwang J, Lee SJ and Im DS: Anti-allergic effects of sesquiterpene lactones from Saussurea costus (Falc.) Lipsch. determined using in vivo and in vitro experiments. J Ethnopharmacol 213: 256-261, 2018.

13. Duraipandiyan V, Al-Harbi NA, Ignacimuthu S and Muthukumar C: Antimicrobial activity of sesquiterpene lactones isolated from traditional medicinal plant, Costus speciosus (Koen ex.Retz.) Sm. BMC Complement Altern Med 12: 13, 2012.

14. Kim DY and Choi BY: Costunolide-A bioactive sesquiterpene lactone with diverse therapeutic potential. Int J Mol Sci 20: E2923, 2019.

15. Rasul A, Parveen S and Ma T: Costunolide: A novel anti-cancer sesquiterpene lactone (Review). Int J Oncol 7: 6-13, 2012.

16. Hua P, Zhang G, Zhang Y, Sun M, Cui R, Li X, Li B and Zhang X: Costunolide induces G1/S phase arrest and activates mitochondrial-mediated apoptotic pathways in SK-MES 1 human lung squamous carcinoma cells. Oncol Lett 11: 2780-2786, 2016.

17. Cai H, He X and Yang C: Costunolide promotes imatinib-induced apoptosis in chronic myeloid leukemia cells via the Bcr/Abl-Stat5 pathway. Phytother Res 32: 1764-1769, 2018.

18. Jeong SJ, Itokawa T, Shibuya M, Kuwano M, Ono M, Higuchi R and Miyamoto T: Costunolide, a sesquiterpene lactone from Saussurea lappa, inhibits the VEGFR KDR/Flk-1 signaling pathway. Cancer Lett 187: 129-133, 2002.

19. Das T, Safferling K, Rausch S, Grabe N, Boehm H and Spatz JP: A molecular mechanotransduction pathway regulates collective migration of epithelial cells. Nat Cell Biol 17: 276-287, 2015.

20. Qin J, Tang J, Jiao L, Ji J, Chen WD, Feng GK, Gao YH, Zhu XF and Deng R: A diterpenoid compound, excisanin A, inhibits the invasive behavior of breast cancer cells by modulating the integrin $\beta 1 / \mathrm{FAK} / \mathrm{PI} 3 \mathrm{~K} / \mathrm{AKT} / \beta$-catenin signaling. Life Sci 93: 655-663, 2013

21. Schmittgen TD and Livak KJ: Analyzing real-time PCR data by the comparative C(T) method. Nat Protoc 3: 1101-1108, 2008.

22. Hamidi H and Ivaska J: Every step of the way: Integrins in cancer progression and metastasis. Nat Rev Cancer 18: 533-548, 2018.

23. Hiraki M, Maeda T, Mehrotra N, Jin C, Alam M, Bouillez A, Hata T, Tagde A, Keating A, Kharbanda S, et al: Targeting MUC1-C suppresses BCL2A1 in triple-negative breast cancer. Signal Transduct Target Ther 3: 13, 2018.

24. Kimani NM, Matasyoh JC, Kaiser M, Brun R and Schmidt TJ: Antiprotozoal sesquiterpene lactones and other constituents from tarchonanthus camphoratus and Schkuhria pinnata. J Nat Prod 81: 124-130, 2018. 
25. Yan Z, Xu T, An Z, Hu Y, Chen W, Ma J, Shao C and Zhu F: Costunolide induces mitochondria-mediated apoptosis in human gastric adenocarcinoma BGC-823 cells. BMC Complement Altern Med 19: 151, 2019.

26. Saosathan S, Khounvong J, Rungrojsakul M, Katekunlaphan T, Tima S, Chiampanichayakul S, Berkland C and Anuchapreeda S: Costunolide and parthenolide from Champi Sirindhorn (Magnolia sirindhorniae) inhibit leukemic cell proliferation in K562 and molt-4 cell lines. Nat Prod Res 28: 1-5, 2019.

27. Hu M, Liu L and Yao W: Activation of $\mathrm{p} 53$ by costunolide blocks glutaminolysis and inhibits proliferation in human colorectal cancer cells. Gene 678: 261-269, 2018.

28. Pitchai D, Roy A and Banu S: In vitro and in silico evaluation of NF-kB targeted costunolide action on estrogen receptor-negative breast cancer cells-a comparison with normal breast cells. Phytother Res 28: 1499-1505, 2014.

29. Ke B, Tian M, Li J, Liu B and He G: Targeting programmed cell death using small-molecule compounds to improve potential cancer therapy. Med Res Rev 36: 983-1035, 2016.
30. Asati V, Bharti SK and Mahapatra DK: Mutant B-Raf kinase inhibitors as anticancer agents. Anticancer Agents Med Chem 16: 1558-1575, 2016

31. Valastyan S and Weinberg RA: Tumor metastasis: Molecular insights and evolving paradigms. Cell 147: 275-292, 2011.

32. Zou Y, Wei J, Xia Y, Meng F, Yuan J and Zhong Z: Targeted chemotherapy for subcutaneous and orthotopic non-small cell lung tumors with cyclic RGD-functionalized and disulfide-crosslinked polymersomal doxorubicin. Signal Transduct Target Ther 3: 32, 2018.

33. Lyu Y, Xiao Q, Yin L, Yang L and He W: Potent delivery of an MMP inhibitor to the tumor microenvironment with thermosensitive liposomes for the suppression of metastasis and angiogenesis. Signal Transduct Target Ther 4: 26, 2019.

(i) (9) This work is licensed under a Creative Common Attribution-NonCommercial-NoDerivatives 4.0 International (CC BY-NC-ND 4.0) License. 